Published as: Van Malderen, L., B. Jourquin, C. Pecheux, I. Thomas, E. Van de Vijver, T. Vanoutrive, A. Verhetsel \& F. Witlox (2013) "Exploring the profession of mobility manager in Belgium and their impact on commuting". Transportation Research A: Policy and Practice. Vol. 55, pp. 46-55.

\title{
EXPLORING THE PROFESSION OF MOBILITY MANAGER IN BELGIUM AND THEIR IMPACT ON COMMUTING
}

\author{
Van Malderen Laurent ${ }^{1} *$ \\ laurent.vanmalderen@uclouvain-mons.be \\ Jourquin Bart $^{1}$ \\ bart.jourquin@uclouvain-mons.be \\ Pêcheux Claude ${ }^{1}$ \\ claude.pecheux@uclouvain-mons.be \\ Thomas Isabelle ${ }^{2}$ \\ isabelle.thomas@uclouvain.be \\ Van De Vijver Elien ${ }^{3}$ \\ elien.vandevijver@ugent.be \\ Vanoutrive Thomas ${ }^{4}$ \\ thomas.vanoutrive@ua.ac.be \\ Verhetsel Ann ${ }^{5}$ \\ ann.verhetsel@ua.ac.be \\ Witlox Frank ${ }^{4}$ \\ frank.witlox@ugent.be \\ * Corresponding author \\ Laurent Van Malderen \\ Université catholique de Louvain - Mons \\ Chaussée de Binche, 151 \\ B-7000 Mons (Belgium) \\ +32 (0)65323424 \\ laurent.vanmalderen@uclouvain-mons.be
}

\footnotetext{
${ }^{1}$ Louvain School of Management, Université catholique de Louvain, Mons.

Chaussée de Binche, 151 B-7000 Mons (Belgium).

${ }^{2}$ Centre for Operations Research and Econometrics \& Department of geography, Université catholique de Louvain, Louvain-la-Neuve.

Voie du Roman Pays, 34 B-1348 Louvain-la-Neuve (Belgium).

${ }^{3}$ Social and Economic Geography Research Group, Universiteit Gent, Ghent.

Krijgslaan, 281 S8 B-9000 Ghent (Belgium).

${ }^{4}$ Department of Transport and Regional Economics, Universiteit Antwerpen, Antwerp.

Prinsstraat, 13 B-2000 Antwerp (Belgium).
} 


\begin{abstract}
This paper aims to explore the profession of mobility manager and to find out whether they achieve (or not) to change the commuting behaviours of employees. To achieve these objectives, we firstly use data of a Belgian mobility survey that contains information about 4,969 workplaces. Then, we use data of a face-to-face survey among 60 mobility managers. The results show that the mobility managers may have an important impact on both the Employer Transport Plan of her/his workplace and the commuting behaviour of employees. We also empirically find out that her/his involvement in managing mobility is important. However, the survey we perform shows that the profession of mobility manager is still a part time function in Belgium and that they only have an advisory role in the decision taken by their workplaces. Therefore, one can conclude that the role of mobility managers is important, but not as important as other factors such as the explicit support of the executive officers.
\end{abstract}

KEYWORDS: Employer Transport Plan (ETP), travel plan, mobility manager, Belgium

\title{
1. Introduction
}

In recent years, the interest brought by companies to the mobility of their employees has steadily increased thanks to the operational benefits mobility can achieve (Roby, 2010), governmental regulations and/or incentives (Enoch and Potter, 2003) and their altruistic sense of responsibility (Cairns et al., 2003). Therefore, an increasing number of companies have implemented an Employer Transport Plan ${ }^{5}$ (ETP) in order to control or reduce the number of their employees commuting solo by car (Van Malderen et al., 2012). The appointment of a member of staff whose work consists of facilitating the implementation of mobility measures (Vanoutrive et al., 2010) - the so-called mobility manager or employee transport coordinator - is one of the actions companies can take to achieve this objective.

Despite numerous papers which focus on ETPs, only a few aims at exploring the role of the mobility manager and her/his impact on the effectiveness of ETPs. To our knowledge, Wachs and Giuliano (1992) is the most comprehensive contribution about mobility managers to date. The authors

\footnotetext{
5 "Employer transport plans" are also known as "travel plans", "site-based mobility management plans", "commuter plans" and "green transport plans" (Enoch, 2012).
} 
survey a sample of people having this function in Southern California and describe the profession and who those people are. They found out that the mobility managers overestimate both the actions of their company and the effectiveness of their ETP. They also conclude that a strong support of mobility managers for ETP is a prerequisite of success. Other papers deal partly with the issue. In the framework of an analysis of ETPs in the UK, Rye (1999a) also describes who mobility managers are. He found that the members of staff who take on the role are often situated low in the organizational hierarchy, although they should operate at managerial level to be effective (Hendricks and Georggi, 2007). Regarding the impact of the mobility managers on the commuting behaviour of employees, Chorus et al. (2006) state in a literature review on travel information that such services may be useful to correct the misperceptions transit travellers have. As providing information is also the job of mobility managers, one can except that she/he may influence the commuting behaviours of employees. In a quantitative analysis on data of a large scale Belgian survey, Van Malderen et al. (2012) do not find a positive effect of the appointment of a mobility manager within companies on the use of alternative modes of transport by the employees. However, this paper does not discuss the endogeneity issue: the impact of the mobility manager may be indirect through the measures he has implemented. In addition, her/his impact may depend on the importance of their involvement.

This paper aims to explore the profession of mobility manager and to find out whether they achieve (or not) to change the commuting behaviours of employees. To achieve these objectives, two analyses are performed. First, data of a survey among 60 mobility managers are used in order to explore the profession of mobility managers in Belgium. Then, data of a large-scale survey among large companies located in Belgium are used in order to find out what impact mobility managers have on both the ETP of her/his company and the commuting behaviour of the employees. An indicator of commuting efficiency is computed for that purpose and to test whether the degree of involvement of the mobility manager impacts the effectiveness of their ETP.

The paper is organized as follows. First, the data and the survey design are described (Section 2). Section 3 presents the methodology of the analyses. Section 4 explores the profession of mobility manager in Belgium and describes which companies appoint a mobility manager and who they are. Section 5 is devoted to the analysis of the relationship that may exist 
between the mobility managers, her/his involvement and the commuting behaviour of the employees. Finally, Section 6 discusses the results and concludes.

\section{Data}

Two datasets are used in this paper: data of a large scale Belgian survey, the home-to-work travel (HTWT) diagnosis, and data of a survey we perform among 60 mobility managers of large companies surveyed in the HTWT diagnosis.

\subsection{HTWT diagnosis}

The HTWT diagnosis is a mandatory survey conducted by the Belgian Federal Public Service 'Mobility and Transport'. The diagnosis is performed every 3 years among all companies located in Belgium which employ at least 100 employees. They have to fill in a questionnaire for every of their workplaces employing at least 30 employees. The workplaces have to give information on both the main mode of transport used by their employees to commute and the mobility measures they have implemented (of which the appointment of a mobility manager is an example). Questions about the workplaces (e.g. number of employees, working schedules of the employees) are also asked. Two diagnoses are available to date (2005 and 2008). They contain data on 3,269 and 3,733 companies respectively. These companies are divided across 7,460 and 9,455 workplaces. Nonetheless, only 4,969 workplaces are surveyed in both diagnoses. We use data about these 4,969 workplaces, knowing that the 2005 database was enriched with a measure of accessibility by rail (Vanoutrive et al., 2012) and that we used the Belgian functional urban regions as defined by Luyten and Van Hecke (i.e. city centre, built-up area, suburb, industrial area and other; 2007) in which the workplaces are located. For more information about the HTWT diagnosis, see Vanoutrive et al. (2010).

\subsection{Survey among mobility managers}

The HTWT diagnosis asked if a mobility manager has been appointed or not by the workplaces. No additional question about the profession is asked. Consequently, we decided to interview 60 of these mobility managers in order to have additional insights about this profession. This survey was performed in 2010. Mobility managers were selected by a judgement sampling as it is appropriated to collect opinions of practitioners. It also allows the obtainment of a bigger wealth of information (Giannelloni and 
Vernette, 2001). The selection criteria were the existence of an ETP within their workplace, the economic sector of their company and its location. We tried to widen the sample depending on these criteria. However, some occurrences were inevitable. In fact, some economic sectors are more important than other in Belgium and some cities concentrate more economic activity than others. As many companies are located there, those cities attract a large number of commuters (Verhetsel et al., 2010). The mobility managers we selected were first contacted with an e-mail containing information on the research and asked for cooperation. Where no reaction came, we contacted them by phone. A large number of mobility managers reacted positively thanks to this direct approach. The most frequent reason of refusal was the lack of time. Table 1 shows the final spread of the sample and Figure 1 shows the geographical location of the sample. 
Table 1 - Spread of the sample across the economic sectors

\begin{tabular}{|l|l|l|l|l|}
\hline Sector & Belgium & $\begin{array}{l}\text { Flemish } \\
\text { Region }\end{array}$ & $\begin{array}{l}\text { Brussels } \\
\text { Capital } \\
\text { Region }\end{array}$ & $\begin{array}{l}\text { Walloon } \\
\text { Region }\end{array}$ \\
\hline Manufacturing & 13 & 4 & 3 & 6 \\
Local Government & 6 & 2 & 1 & 3 \\
Public administration and defence; social security & 6 & 3 & 2 & 1 \\
Other community, social and personal services & 4 & 1 & 1 & 2 \\
University & 4 & 2 & 1 & 1 \\
Health & 3 & 2 & 0 & 1 \\
Electricity, gas and water & 3 & 0 & 2 & 1 \\
Finance & 3 & 0 & 2 & 1 \\
Non Profit & 3 & 1 & 1 & 1 \\
Public transport companies & 3 & 1 & 1 & 1 \\
Real estate, renting and producer services & 3 & 1 & 2 & 0 \\
Wholesale and retail; repair of motor vehicles & 3 & 1 & 1 & 1 \\
and consumer goods & 2 & & \\
Construction & 2 & 0 & 2 & 0 \\
Transport and warehousing, communication & 2 & 2 & 0 & 0 \\
Police & 1 & 0 & 0 & 1 \\
Post & 1 & 0 & 1 & 0 \\
\hline TOTAL & $\mathbf{6 0}$ & $\mathbf{2 0}$ & $\mathbf{2 0}$ & $\mathbf{2 0}$ \\
\hline
\end{tabular}

Figure 1 - Geographical location of the sample ( $A=$ Antwerp, $B=$ Brussels, $\mathrm{C}=$ Charleroi, $\mathrm{G}=$ Ghent, $\mathrm{L}=$ Liège)

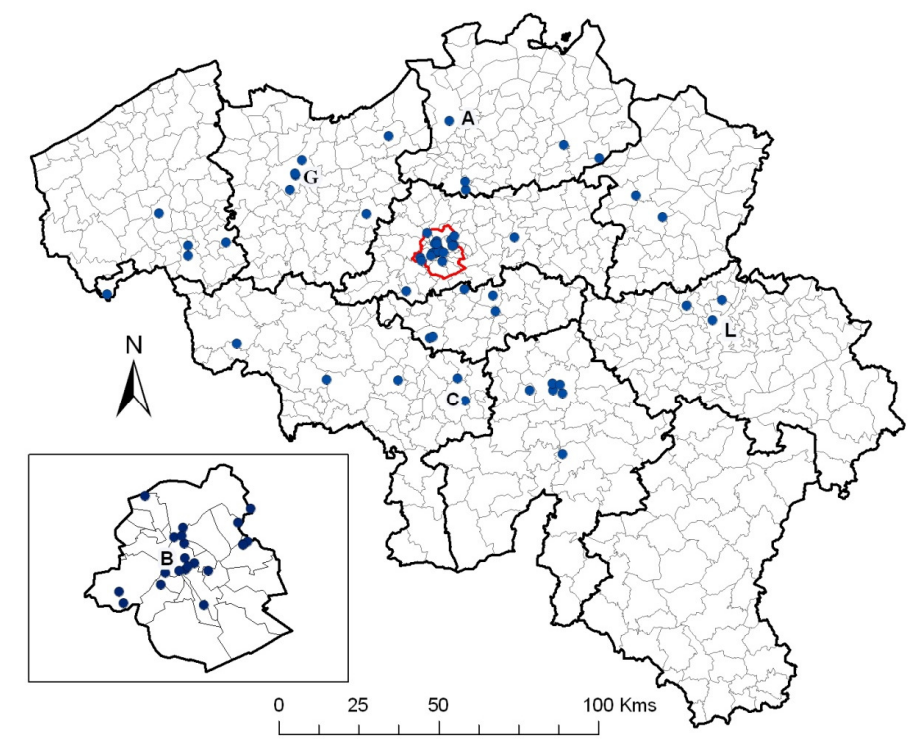


The survey consisted of face-to-face interviews. They were based on a semidirective questionnaire. The questionnaire contains two types of questions: open questions and multiple-choice questions. These questions focus on the following themes: activity spheres of the mobility manager, original and current motivations of the ETP, benefits the ETP provided to the company and a description of the profession. We also asked the mobility managers to rate the acceptance/acceptability of some mobility measures by both the employees and the employers of their company, and to rate the effectiveness of some mobility measures. A 5-points Likert ranking scale was used: rank 1 represents a high unacceptance, while rank 5 a high acceptance. The choice of five response categories was motivated by its easiness and quickness to be used by the respondents (Preston and Colman, 2000). Table 2 shows the mobility measures the mobility managers have to rate. This list is based on both an exploratory factor analysis of mobility measures of the Belgian mobility diagnosis (Vanoutrive et al., 2010), and a classification made by Rye (1999b). Note that some mobility measures are clustered because, as shown in Van Malderen et al. (2012), the companies located in Belgium tend to implement similar measures. Interviewees were asked to reply whether or not the measures of the categories have been implemented in their company. Despite these predefined questions, time was also left for digression and secondary questions. In total, the interviews lasted 50 minutes on average. 
Table 2 - Categories of mobility measures

\begin{tabular}{|l|}
\hline $\begin{array}{l}\text { Financial incentives to the use of } \\
\text { alternative modes of transport }\end{array}$ \\
\hline $\begin{array}{l}\text { Dissemination of information about } \\
\text { alternative modes of transport }\end{array}$ \\
\hline Offering facilities to encourage cycling \\
\hline Provision of bicycles/repairs facilities \\
\hline $\begin{array}{l}\text { Organization of carpooling/creation of a } \\
\text { carpooling database }\end{array}$ \\
\hline $\begin{array}{l}\text { Encouragement to use alternatives mode } \\
\text { of transport (including for work trips) }\end{array}$ \\
\hline Guaranteed return trip for carpoolers \\
\hline Organization of mobility days \\
\hline Parking management (restriction) \\
\hline $\begin{array}{l}\text { Collaboration with other companies/the } \\
\text { public transport }\end{array}$ \\
\hline
\end{tabular}

\section{Methodology}

Two types of methodology are used. First, we compute a commuting efficiency rating for each company of the HTWT diagnosis. These ratings are used in order to test whether the commuting behaviours of the employees of the companies with a mobility manager is more efficient (or not) than those without a mobility manager. Secondly, the data of the survey among mobility managers are used in order to assess the involvement of the person in her/his tasks. Expert judgement and contents analysis are used to achieve this objective. Then, we test whether the commuting behaviours of the employees of the companies with an involved mobility manager is more efficient than the other companies.

\subsection{The commuting efficiency of a company}

The commuting efficiency of a company can be defined as the minimization within the company of the use of transportation resources for commuting to and from work, considering the background conditions at the workplace (Nozick et al., 1998). It implies a minimization of car use in favour of alternative modes of transport, which is the objective of any ETP. Note that the commuting efficiency as defined here only considers efficiency in travel behaviours. Other ways to minimize car use (e.g. telecommuting or teleworking) are not taken into account in this paper.

Data Envelopment Analysis (DEA) is used to compute commuting efficiency ratings. DEA is a linear programming method that calculates the 
relative efficiency of $j$ Decision Making-Units (DMUs) in producing one (or multiple) output(s), $y_{r j}$, with one (or several) input(s), $x_{i j}$. Two different approaches exist: (a) an input-oriented DEA, which defines the efficiency as the success of the DMU $j$ to minimize $i$ inputs given $r$ outputs; and (b) an output-oriented DEA, which defines the efficiency as the success of the DMU $j$ in maximising $r$ outputs given $i$ inputs (Farrell, 1957). According to the above definition of commuting efficiency, one single output, $y_{r j}$, is considered: the use of transportation resources. A company has to minimise this output in order to be considered efficient in commuting. As minimising the use of transportation resources is equivalent to maximising the number of employees-per-vehicle (epv), the output oriented DEA method is appropriated if this new output is considered. The number of epv is calculated by dividing the number of employees using other modes of transport than the single occupied car by the number of employees driving to work alone. The inputs, $x_{i j}$, represent the background conditions at a workplace that favour (or disfavour) the use of alternative modes of transport to solo driving. Three inputs were considered: the on-site parking scarcity ${ }^{6}$, the accessibility by rail and the households' satisfaction with cycling facilities ${ }^{7}$. This choice was motivated by the high correlation of these background variables with the use of the three most popular modes of transport to commute in Belgium (i.e. car, train, and bicycle ${ }^{8}$ ). In fact, each of these inputs is the main worksite-related determinant of the use of the car (Hole, 2004; Van Exel and Rietveld, 2009), the train (Prioni and Hensher, 2000, Vanoutrive et al., 2012) and the bicycle (Kingham et al., 2001; Vandenbulcke et al., 2011). The data about both the output and inputs come from the HTWT diagnosis.

Following the linear fractional programming of Cooper et al. (2004), and adding a scale factor, $s$, the generic output oriented DEA model with $r$ outputs is written as:

$$
\operatorname{Min} \frac{\sum_{i} v_{i} x_{i j}-s}{\sum_{r} u_{r} y_{r j}}
$$

subject to the constraints:

\footnotetext{
${ }^{6}$ The on-site parking scarcity is calculated here as the number of employees per on-site car parks.

7 The household's satisfaction with cycling facilities is the ratio between the percentage of households satisfied with the cycling facilities and those unsatisfied per Belgian municipalities (STATBEL, 2001).

${ }^{8}$ According to the 2008 HTWT diagnosis, $82 \%$ of the commuters use one of these modes of transport.
} 


$$
\begin{aligned}
& \frac{\sum_{i} v_{i} x_{i j}-s}{\sum_{r} u_{r} y_{r j}} \geq 1 \quad \text { for } j=1, \ldots, \mathrm{n} \\
& u_{r}, v_{i} \geq \varepsilon \geq 0 \quad \text { for all } i \text { and } r
\end{aligned}
$$

where $u_{r}$ is the weight of the $r^{\text {th }}$ output, $v_{i}$ the weight of the $i^{\text {th }}$ input and $\varepsilon$ a small positive number which avoids ignoring any inputs or outputs. The scale factor, $s$, takes into account the return to scale. It models the non-linear productivity of inputs: as the background conditions improve, it may not be possible for the number of epv to improve at the same rate (Nozick et al., 1998). Constraint (Eq. 2) limits the efficiency ratings to greater than or equal to one. As the objective function (1) has to be minimized, a low value of the rating indicates a high commuting efficiency. A rating of 1 is attributed to the most efficient DMUs. In that case, those DMUs have reached the efficiency frontier: no additional output can be formed given the inputs. In our case, this means that the number of epv of those companies can not be improved without increasing the inputs. Note that the DEA ratings assess the relative efficiency of the DMUs. This implies that each DMU is compared to the other ones of the sample: their efficiency is evaluated given both the outputs and inputs of the other one. As the objective of the paper is to perform comparisons between companies of the sample, this technique is appropriated. Finally, constraint (3) ensures for non-negative weights.

\subsection{Involvement of the mobility manager}

The involvement of the mobility manager in managing mobility is assessed using the expert judgment method. Involvement is defined as time and/or intensity of effort expended in the undertaking of behaviours (Stone, 1984). Three groups of mobility managers are defined beforehand and based on the level of involvement of the person: strongly involved; moderately involved and lowly involved. Then, two judges (Judge 1 and Judge 2) separately classify the mobility manager into one of the three groups defined. Judge 1 was chosen because of his expertise on the research on involvement and Judge 2 because of his expertise on employer transport plan. Their classification is performed by content analyses of the transcription of the interviews. Content analysis is a method that codifies texts into different groups depending on selected criteria (Weber, 1990). The involvement of the mobility manager in managing mobility is used as a criterion here. 
Highly involved mobility managers are those who are able to give a lot of information on the issue, elaborate on their arguments, take different criteria into consideration and show a good and a precise knowledge of the issue. These managers spent more time discussing the issues than the others. To the contrary, lowly involved managers have a broader and less detailed view of the issue; they provide less information and give shorter answers to the questions. They are less aware of the various dimensions of the issue. The classifications made by the two judges are then compared. In case of no agreement, the interview is submitted to a second content analysis. If no agreement is obtained after this second round, the interviewee is excluded from the sample.

\section{The profession of mobility manager}

\subsection{The companies with a mobility manager}

Four hundred seventy-six workplaces have appointed a mobility manager in the HTWT database we use in this paper (i.e. the one which only considers the workplaces which have been surveyed in 2005 and in 2008). This represents 9.52 percents of the workplaces of the sample. This percentage is somewhat higher than in the whole 2008 HTWT diagnosis in which only 6.95 percents of the workplaces have appointed a mobility manger. Comparatively, 3.61 percent of the 7,460 workplaces surveyed in the 2005 HTWT have declared the appointment of such a member of staff. These percentages show that the number of mobility managers has increased in Belgium. Table 3 shows some descriptive statistics about the 476 workplaces that have appointed a mobility manager in our sample and compare them with those of the workplaces without a mobility manager. We can observe that the former workplaces are more likely to be located in the city centres and in the agglomerations than the latter. They also have more employees. We observe that the workplaces with a mobility manager implement more mobility measures than those without. In the same way, the car parks are scarcer in those workplaces. They do not have more favourable background conditions: the average rail accessibility of those workplaces is not significantly higher and the average satisfaction with cycling facilities is even lower. Finally, there is no significant difference in the average number of $e p v$ of both groups. This would suggest that the appointment of a mobility manager make no difference. However, this observation is based on comparisons of averages, which do not take into account the background conditions at workplaces. Section 5 addresses this issue. . 
Table 3 - Descriptive statistics about the workplaces surveyed in both the 2005 and 2008 HTWT diagnosis: status in 2008

\begin{tabular}{|c|c|c|c|c|c|c|c|}
\hline \multirow[b]{2}{*}{ Variable } & \multicolumn{3}{|l|}{ Mean } & \multicolumn{2}{|c|}{ Median } & \multicolumn{2}{|c|}{ Std. Dev. } \\
\hline & $\begin{array}{l}\text { With } \\
\text { MM }^{\mathrm{a}}\end{array}$ & $\begin{array}{l}\text { Without } \\
\mathrm{MM}^{\mathrm{a}}\end{array}$ & Diff. & $\begin{array}{l}\text { With } \\
\text { MM }^{\text {a }}\end{array}$ & $\begin{array}{l}\text { Without } \\
\text { MM }^{\mathrm{a}}\end{array}$ & $\begin{array}{l}\text { With } \\
\text { MM }^{\text {a }}\end{array}$ & $\begin{array}{l}\text { Without } \\
\text { MM }^{\mathrm{a}}\end{array}$ \\
\hline Rail accessibility $^{b}$ & 0.01 & -0.01 & 0.02 & 0.20 & 0.24 & 0.79 & 0.99 \\
\hline $\begin{array}{l}\text { On-site parking } \\
\text { scarcity }\end{array}$ & 0.47 & 0.79 & $-0.32 * * *$ & 0.31 & 0.56 & 0.71 & 1.86 \\
\hline $\begin{array}{l}\text { Satisfaction with } \\
\text { cycling facilities }^{\mathrm{c}, \mathrm{d}} \\
\text { Type of urban area }\end{array}$ & 49.05 & 50.77 & $-1.72 *$ & 52.01 & 53.89 & 20.07 & 20.92 \\
\hline City centre & 51.68 & 34.92 & $16.76 * * *$ & 100 & 0 & 50.02 & 47.67 \\
\hline Agglomeration & 26.68 & 19.10 & $7.58 * * *$ & 0 & 0 & 44.28 & 39.31 \\
\hline Suburbs & 6.31 & 9.66 & $-3.35 * *$ & 0 & 0 & 24.33 & 29.54 \\
\hline Industrial zone & 7.14 & 14.18 & $-7.04 * * *$ & 0 & 0 & 25.75 & 34.89 \\
\hline $\begin{array}{l}\text { Other urban } \\
\text { area }\end{array}$ & 8.19 & 22.14 & $-13.95 * * *$ & 0 & 0 & 27.45 & 51.53 \\
\hline $\begin{array}{l}\text { Number of } \\
\text { employees }\end{array}$ & 339.59 & 195.94 & $143.7 * * *$ & 100 & 117 & 742.7 & 292.1 \\
\hline Number of $e p v$ & 2.42 & 2.19 & 0.23 & 3.16 & 4.97 & 1.56 & 1.35 \\
\hline $\begin{array}{l}\text { Number of mobility } \\
\text { measure } \\
\text { implemented }\end{array}$ & 6.57 & 3.18 & $3.39 * * *$ & 7 & 3 & 4.03 & 2.53 \\
\hline
\end{tabular}

\subsection{The mobility manager}

The survey among mobility managers (see 2.2.) shows that the profession of mobility manager is a part-time function in Belgium. In fact, none of the 60 mobility managers interviewed work full time on the ETP of their company. About 73 percents of them have been appointed mobility managers because of the connections between their (previous) function and the one of mobility manager (e.g. access to information about employees). Nine percents of them took the initiative and proposed to the management the creation of the function. The remaining 18 percent have applied to a vacancy. There is also not a unique department where the mobility manager operates: one third of the mobility managers interviewed operate from the human resources department, one fifth from the environment department, and the remaining from other departments (facilities management, communication and mobility when it exists). As regards with their role in the development of the ETP, 69 percents declared that they only have an advising role. They propose 
mobility measures or mobility initiatives to the management who take the final decision. Only 25 percents consider their function as a decision-making one. It follows from this advising role that the majority of the mobility managers interviewed do not have financial resources at their disposable. In fact, 53 of them ( $88 \%$ of the sample) declared that they have to use existing resources of the companies (e.g. own construction workers and material if they want to build bicycle shelters) or to ask for budget to the management. There is therefore no budget allocated to the ETP in those companies. Only seven mobility managers have a mobility budget at their disposal. However, they are working for workplaces that have got grants from the Flanders Region.

The mobility managers surveyed were asked to rate the effectiveness and the acceptance/acceptability of some mobility measures by both the employees and the employers (see 2.2). Table 4 presents the average ratings. An average ranking higher than 3 means that the measure is accepted/efficient. An average ranking lower than 3 means that the measure is unaccepted/inefficient. Besides parking management, mobility managers rate favourably the acceptances of mobility measures. The same is true for their effectiveness: all the mobility measures are considered effective in reducing the car use. 
Table 4 - Ratings of the mobility measure by the mobility managers

\begin{tabular}{|c|c|c|c|}
\hline \multirow{2}{*}{ Measure } & \multicolumn{2}{|c|}{ Acceptance/acceptability } & \multirow{2}{*}{ Effectiveness } \\
\hline & Employees & Employers & \\
\hline \multicolumn{4}{|l|}{ Financial incentives to the use of } \\
\hline alternative modes of transport & 4.69 & 3.79 & 4.28 \\
\hline Facilities to encourage cycling & 4.42 & 4.00 & 3.83 \\
\hline Provision of bicycles/repairs facilities & 4.18 & 3.5 & 3.60 \\
\hline Dissemination of information about & & & \\
\hline alternative modes of transport & 4.14 & 4.4 & 3.51 \\
\hline Guaranteed return trip for carpoolers & 3.95 & 3.90 & 3.29 \\
\hline $\begin{array}{l}\text { Encouragement to use alternatives } \\
\text { mode of transport (including for work } \\
\text { trips) }\end{array}$ & 3.91 & 4.28 & 3.70 \\
\hline Organization of carpooling/creation of & & & \\
\hline a carpooling database & 3.90 & 3.87 & 3.20 \\
\hline $\begin{array}{l}\text { Collaboration with other companies/ } \\
\text { public transport }\end{array}$ & 3.89 & 3.95 & 3.44 \\
\hline Organization of mobility days & 3.74 & 3.15 & 3.42 \\
\hline Parking management (restriction) & 2.46 & 3.16 & 3.78 \\
\hline
\end{tabular}

Scale 1-5 (1= high unacceptance/ineffectiveness, $5=$ high acceptance/effectiveness)

\section{The impact of the mobility managers on commuting}

\subsection{Commuting efficiency ratings}

The DEA model (Section 3.1.) computes commuting (relative) efficiency

ratings for the 4,969 workplaces which have been surveyed in both the 2005 and 2008 diagnoses. A value of 1 is attributed to the most efficient companies of the sample. A rating higher than 1 quantifies the relative inefficiency of a workplace. For instance, a workplace with a DEA rating of 3 has to increase by $200 \%$ its number of $e p v$ to be considered as efficient. In other words, potential for a reduction in single-occupancy car use exists within the workplaces that do not have a rating of 1 . Note that a higher commuting efficiency does not systematically mean a higher number of $e p v$. In fact, a company could be considered efficient despite a low number of epv if their background conditions are unfavourable to the use of alternative modes of transport (e.g. if they face either poor rail accessibilities, low satisfaction with cycling facilities, plentiful on-site car parks or any combination of the three). Thus, their background conditions do not allow a greater use of car alternatives. On the contrary, some companies with a high number of epv can be considered as not efficient if they simply do not take advantage of their favourable background conditions. 
The DEA ratings of each workplace are not reported here ${ }^{9}$. A large range of values is computed. Comparisons of means and Wilcoxon tests show that the workplaces located in city centres and in the agglomerations as defined by Luyten and Van Hecke (2007) have lower DEA ratings than the other companies. The map of the ratings of the workplaces located in Brussels and its close vicinity (in which there is a high concentration of workplaces surveyed by the HTWT diagnoses) illustrates best this phenomenon (Figure 2). This result is consistent with those published by Verhetsel et al. (2010): the use of car to commute is more frequent in the companies located outside the city centre and the agglomerations even though similar alternatives exist.

Figure 2 - Commuting efficiency ratings of the workplaces located in Brussels and its close vicinity

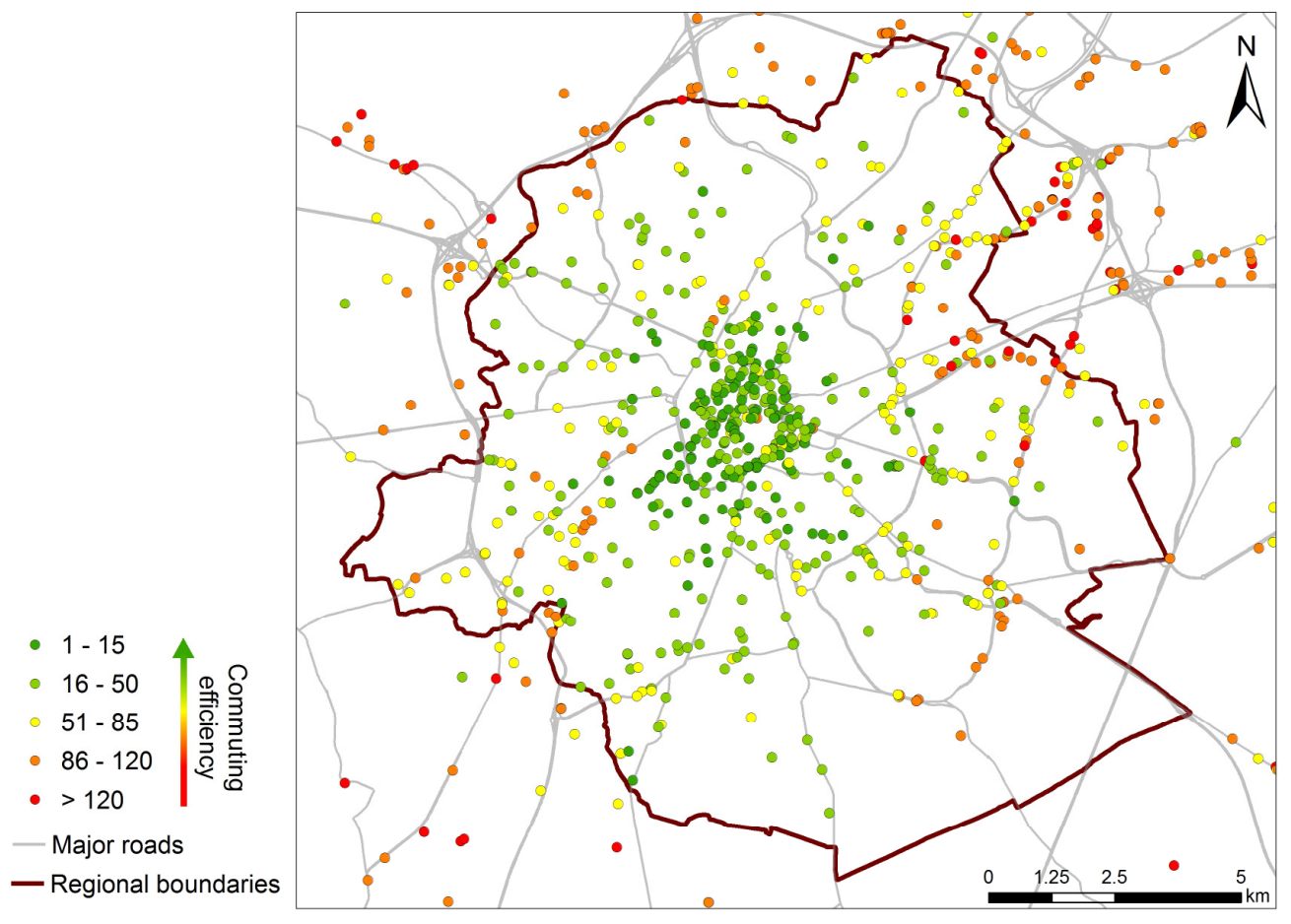

\subsection{Commuting efficiency and mobility managers}

The workplaces of the HTWT diagnosis are divided into 2 groups: those which have appointed a mobility manager and those which haven't. A comparison of means is then used in order to compare the DEA ratings of these two groups. The exercise is performed for the pooled sample and also per type of urban area where the workplaces are located (Table 5). If we consider the whole sample, the results show that the workplaces which have

\footnotetext{
${ }^{9}$ They are available upon request to the first author of this article.
} 
appointed a mobility manager have on average lower DEA ratings. This means that their employees commute more efficiently given the background condition at the workplaces than the employees of the workplaces without a mobility manager. If we analyse the results per type of urban areas, we observe that this result is only valid for the workplaces located in city centres, in the agglomerations and those located in other urban areas. The DEA ratings of the workplaces located in the suburbs and in the industrial zones do not differ depending on whether the workplace has appointed a mobility manager or not. However, note that the appointment of a mobility manager is rare (Table 4).

Table 5 - DEA ratings and appointment of a mobility manager: comparison of means

\begin{tabular}{|c|c|c|c|c|c|}
\hline Mobility Manager & $N$ & Mean & Std. Dev. & Min. & Max. \\
\hline \multicolumn{6}{|l|}{ All sample } \\
\hline Yes & 476 & 57.87 & 31.94 & 1 & 139 \\
\hline No & 4493 & 68.78 & 33.98 & 1 & 142.9 \\
\hline Diff. & - & $10.90^{* * *}$ & 33.78 & - & - \\
\hline \multicolumn{6}{|c|}{ Workplaces located in city centres } \\
\hline Yes & 246 & 59.71 & 30.79 & 2.11 & 133.1 \\
\hline No & 1569 & 64.59 & 34.76 & 1 & 142.9 \\
\hline Diff. & - & $4.88^{* * *}$ & 34.25 & - & - \\
\hline \multicolumn{6}{|c|}{ Workplaces located in the agglomerations } \\
\hline Yes & 127 & 48.23 & 34.14 & 2.21 & 139 \\
\hline No & 858 & 66.14 & 38.36 & 1 & 142.9 \\
\hline Diff. & - & $17.92^{* * *}$ & 37.84 & - & - \\
\hline \multicolumn{6}{|c|}{ Workplaces located in the suburbs } \\
\hline Yes & 30 & 70.62 & 26.31 & 17.75 & 123.7 \\
\hline No & 434 & 78.86 & 31.67 & 1 & 137.3 \\
\hline Diff. & - & 8.24 & 31.62 & - & - \\
\hline \multicolumn{6}{|c|}{ Workplaces located in the industrial zones } \\
\hline Yes & 34 & 66.90 & 24.57 & 1 & 128.2 \\
\hline No & 642 & 73.15 & 28.91 & 1 & 134.4 \\
\hline Diff. & - & 6.25 & 28.71 & - & - \\
\hline \multicolumn{6}{|c|}{ Workplaces located in other urban areas } \\
\hline Yes & 37 & 60.04 & 34.46 & 2.65 & 133.9 \\
\hline No & 995 & 70.46 & 31.28 & 1 & 142.9 \\
\hline Diff. & - & $10.41^{* *}$ & 31.34 & - & - \\
\hline
\end{tabular}

Significant at 0.1 level; ${ }^{* *}$ Significant at 0.05 level; *** Significant at 0.01 level.

\subsection{Commuting efficiency and involvement of the mobility manager}

The classification of the mobility managers in three states of involvement is performed by the expert judgment method and content analyses (see 3.2.). 
The impact of the involvement of the mobility manager is assessed by inter group comparisons: we compare the commuting efficiency of the three clusters. Note however, that the DEA ratings of this analysis are not those used in the previously (5.2). In fact, we compute new ratings by considering only the companies of the survey we perform. As the DEA method computes relative ratings, this allows only the companies of the sample to be compared with themselves. Non-parametric statistics are used to perform the comparisons because they are appropriated for small samples (Siegel and Castellan, 1988). Kruskall-Wallis and median tests (Table 6) are firstly performed. Note that we dropped 20 observations because we were not able to classify the mobility manager: the interviews are too short to perform a content analysis or no convergence appears among the judges. No statistical evidence of inter-groups differences in commuting efficiencies is found. However, the mean score of the cluster of the companies with highly involved mobility managers suggests that they could be drawn from another population than the companies of the other clusters.

Table 6 - Involvement of the mobility managers: group comparisons

\begin{tabular}{|c|c|c|c|}
\hline \multirow{2}{*}{ Degree of involvement } & \multirow{2}{*}{$N^{a}$} & $\begin{array}{c}\text { Kruskall-Wallis } \\
\text { test }\end{array}$ & $\begin{array}{c}\text { Median } \\
\text { test }\end{array}$ \\
\hline & & $\begin{array}{l}\text { Mean } \\
\text { score }\end{array}$ & Mean score \\
\hline a) High & 16 & 20.92 & 0.33 \\
\hline b) Medium & 13 & 25.00 & 0.56 \\
\hline c) Weak & 11 & 25.37 & 0.67 \\
\hline$P$-value $e^{b}$ & & 0.57 & 0.17 \\
\hline
\end{tabular}

${ }^{a}$ All 45 companies classified on the basis of the involvement of the mobility manager (see 3.3.) have not be taken into account because of missing data for the calculation of the DEA ratings.

${ }^{\mathrm{b}}$ One-tailed.

Secondly, pairwise comparisons are performed by means of Wilcoxon and median tests (Table 7). Despite that the Wilcoxon tests do not show significant differences among the clusters, the median test confirms the above hypothesis. In fact, it appears that the commuting efficiency is higher in the companies with a highly involved mobility manager than in the companies of the other groups. Hence, the employees of the companies with a highly involved mobility managers use less the car to commute than the employees of the other companies. However, note that the Median test is less powerful than the Wilcoxon one and that our final sample size is also rather small (only 40 observations). Consequently more research on this field is probably required for a better understanding of the part played by the mobility manager in mobility plan success. 
Table 7 - Involvement of the mobility managers: pairwise comparisons

\begin{tabular}{|l|l|l|}
\hline \multirow{2}{*}{ Degree of involvement } & \multicolumn{1}{|c|}{$\begin{array}{c}\text { Wilcoxon } \\
\text { test }\end{array}$} & $\begin{array}{c}\text { Median } \\
\text { test }\end{array}$ \\
\cline { 2 - 3 } & Prob. $\leq^{\mathrm{a}}$ & Prob. $\leq^{\mathrm{a}}$ \\
\hline a) Medium $v s$ weak & 0.49 & 0.50 \\
b) High $v s$ medium & 0.20 & $0.08^{*}$ \\
c) High $v$ weak & 0.19 & $0.07^{*}$ \\
\hline
\end{tabular}

a One-tailed.

${ }^{*}$ Significant at 0.1 level; ${ }^{* *}$ Significant at 0.05 level; *** Significant at 0.01 level.

\section{Discussion and conclusion}

This paper aims at exploring the profession of mobility manager and at finding out whether they achieve (or not) to change the commuting behaviours of the employees. To achieve these objectives, data of a large scale mobility survey performed in Belgium and a survey we perform among 60 mobility managers are used. Three main results arise.

First, the mobility manager may have a real impact on both the ETP of his workplace and on the effectiveness of the plan (i.e. on the commuting behaviour of the employees). In fact, we observe that the workplaces that have appointed a staff member for this task are more active in the promotion of mobility: they implement more mobility measures and the car parks are scarcer there. As a result, the employees of those workplaces use more car alternatives than those of the other workplaces even when the background conditions at the workplaces are less favourable to these car alternatives. In addition, this impact is larger at the workplace where the mobility manager is highly involved in his function. Therefore, workplaces should appoint a mobility manager who is actively interested in the role (Rye, 1999a).

Secondly, we put into perspective the importance of the mobility manager by exploring this job function. We find that, in Belgium as in the USA (Wachs and Giuliano, 1992) and in the UK (Rye, 1999a), this task often comes in addition to other responsibilities and that the mobility managers only have an advisory role and are not responsible for the final decisions. They also do not have a specific mobility budget at their disposal. Thus, the success of an ETP is probably more the result of several factors than the results of the action of the sole mobility manager. This would confirm both the findings of Rye (2002) for who a staff member dedicated to mobility can be of great benefit and those of Hendricks and Joshi (2004), who state that the role of the mobility manager is important but not as strong as other 
factors. As mobility managers only have an advisory role, we can conclude that, among other factors, the support of the executive officers is also important. Hendricks and Joshi (2004) include support staff and good advocacy as important success factors.

Finally, we also show that the mobility managers probably face a lack of tools to evaluate the success of their policy. Similarly to Wachs and Giualino (1992), we find that they rate favourably the effectiveness of the mobility measures, as well as their acceptance by both employees and employers. However, as differences are observed in the commuting efficiency ratings where the background conditions at the workplaces are controlled, this suggests that differences in the effectiveness of ETP exist. Therefore, one can assume that the mobility managers overestimated the effectiveness of the mobility measures. Mobility surveys such as the Belgian HTWT diagnosis, which has been introduced in 2005, could perhaps take on this role in the future, as it has to be filled in on a regular basis.

\section{Acknowledgements}

This research was conducted within the framework of the ADICCT-project (Assessing and Developing Initiatives of Companies to control and reduce Commuter Traffic), which is financed by Belgian Science Policy in the Science for a Sustainable Development research programme. We are also grateful to the companies surveyed for their collaboration and to the FPS Mobility and Transport. 


\section{References}

Cairns, S., C. Newson and A. Davis (2010) Understanding successful workplace travel initiatives in the UK. Transportation Research A 44, 473494.

Chorus, G., E.J.E. Molin and B. Van Wee (2006) Travel information as instrument to change car-drivers' travel choices: a literature review. European Journal of Transport and Infrastructure Research 6, 335-364.

Cooper, W., M. Seiford and J. Zhu (2004) Handbook on Data Envelopment Analysis. Kluwer's International Series.

Enoch M. and S. Potter (2003) Encouraging the commercial sector to help employees to change their travel behaviour. Transport Policy 10, 51-58.

Enoch M. (2012) Sustainable Transport, Mobility Management and Travel Plans. Ashgate, Farnham.

Farrel, M.J. (1957) The measurement of productive efficiency. Journal of the Royal Statistical Society A 120 (3), 253-290.

Giannelloni, J.L. and E. Vernette (2001) Etudes de marché. Vuibert, 239 (in French).

Hendricks, S.J. and A. Joshi (2004) Commuter choice program - Case study development and analysis. Tampa, FL: Center for Urban Transportation Research. University of South Florida.

Hendricks, S.J. and N.L. Georggi (2007) Documented impact of transportation demand management programs through the case study method. Journal of Public Transportation 10, 79-98.

Hole, A.R. (2004) Forecasting the demand for an employee park and ride service using commuter's stated choices. Transport Policy 11 (4), 355-362.

Kingham, S., J. Dickinson and S. Copsey (2001) Travelling to work: will people move out of their cars? Transport Policy 8, 151-160.

Luyten, S. and E. Van Hecke (2007) De Belgische stadsgewesten 2001. Statistics Belgium working paper (in Dutch).

Nozick, L. K., H. Borderas and A.H. Meyburg (1998) Evaluation of travel demand measures and programs: a data envelopment analysis approach. Transportation Research A 32 (5), 331-343.

Preston, C.C. and A.M. Colman (2000) Optimal number of response categories in rating scales: reliability, validity, discriminating power, and respondent preferences. Acta Psychologica 104, 1-15. 
Prioni, P. and D.A. Hensher (2000) Measuring service quality in scheduled bus services. Journal of Public Transportation 3 (2), 51-74.

Roby, H. (2010) Workplaces travel plans: past, present and future. Journal of Transport Geography 18 (1), 23-20.

Rye, T. (1999a) Employer transport plan - a case for regulation? Transport Reviews 19, 13-31.

Rye, T. (1999b) Employer attitudes towards employer transport plans: a comparison of UK and Dutch experience. Transport Policy 6, 183-196.

Rye, T. (2002) Travel plans: do they work? Transport Policy 9, 287-298.

Siegel, S. and N.J. Castellan (1988) Nonparametric statistics for the behavioral sciences. McGraw-Hill Humanities/Social Sciences, London.

Statbel (2001) Enquête socio-économique générale 2001. Statbel (in French).

Stone, R.N. (1984) The marketing characteristics of involvement. In: Kinnear, T.C. (Ed.), Advances in Consumer Research 11, provo UT: Association for consumer research, 210-215.

Van Exel, N.J.A and P. Rietveld (2009) Could you also made this trip by another mode? An investigation of perceived travel possibilities of car and train travelers on the main travel corridors to the city of Amsterdam, The Netherlands. Transportation Research A 43 (4), 374-385.

Vandenbulcke, G. , C. Dujardin, I. Thomas, B. De Geus, B. Degraeuwe, R. Meeusen and L. Int Panis (2011) Cycle commuting in Belgium: spatial determinants and 're-cycling' strategies. Transportation Research A 45 (2), 118-137.

Vanoutrive, T., L. Van Malderen, B. Jourquin, I. Thomas, A. Verhetsel and F. Witlox (2010) Mobility management measures by employers: overview and exploratory analysis for Belgium. European Journal of Transport and Infrastructure Research 10 (2), 121-141.

Vanoutrive, T., L. Van Malderen, B. Jourquin, I. Thomas, A. Verhetsel and F. Witlox (2012) Rail commuting to workplaces in Belgium: a multilevel approach. International Journal of Sustainable Transportation 6 (2), 67-87.

Van Malderen L., B. Jourquin, I. Thomas, T. Vanoutrive, A. Verhetsel and F. Witlox (2012) On the mobility policies of the companies: what are the good practices? The Belgian Case. Transport Policy 21, 10-19. 
Verhetsel, A., I. Thomas and M. Beelen (2010) Commuting in Belgian metropolitan areas. Journal of Transport and Land Use 2 (3/4), 109-131. Wachs, M. and G. Giuliano (1992) Employee transport coordinators: a new profession in Southern California. Working Paper No. 99, The University of California Transportation Center.

Weber, R.P. (1990) Basic Content Analysis ( $2^{\text {nd }}$ ed.). Sage University Paper Series on Quantitative Applications in the Social Sciences, Series No. 49, Newbury Park, CA: Sage. 